\title{
Structural Analysis and Characterization of PZT Fiber Fabricated by Electrospinning
}

\author{
Chun Kil Park***, Ji Sun Yun*`, Young Hun Jeong*, Joong-Hee Nam*, Jeong Ho Cho*, Jong-Hoo Paik*, \\ and Dae young Jeong**
}

*Electronic Materials Convergence Division, Korea Institute of Ceramic Engineering and Technology, Seoul 153-023, Korea

**Korea Department of materials Science and Engineering, In-ha University, Incheon 402-751, Korea

(Received September 30, 2013; Revised November 3, 2013; Accepted November 21, 2013)

\author{
Electrospinning법으로 제조된 PZT 섬유의 구조분석 및 특성평가
박춘길*** · 윤지선 *† · 정영훈* · 남중희* · 조정호* · 백종후* · 정대용**
*한국세라믹기술원 전자소재융합본부
**인하대학교 신소재공학과
(2013년 9월 30일 접수 ; 2013년 11월 3일 수정 ; 2013년 11월 21일 채택)

\begin{abstract}
Currently, piezoelectric ceramics are being applied in various fields, such as ultrasonic sensors, vibration devices, sound filters, and various energy conversion devices. Flexible piezoelectric ceramics are widely studied in an effort to mitigate the disadvantages of their brittle and inductile properties. Structural damage to piezoelectric fibers is much less than that to thin films when piezoelectric fibers are twisted or bent. Therefore, stretchable devices can be fabricated if piezoelectric fibers are obtained using an elongated substrate. In this study, sintering processes of $\mathrm{PZT}\left(\mathrm{Pb}\left(\mathrm{Zr}_{0.53} \mathrm{Ti}_{0.47}\right) \mathrm{O}_{3}\right)$ fibers prepared by electrospinning were optimized through the TGA and XRD analyses. The crystal structure and microstructure of the piezoelectric fibers were investigated by XRD, FE-SEM and TEM.
\end{abstract}

Key words: PZT, Electrospinning, Nanofibers

\section{1. 서 론}

$\operatorname{PZT}\left(\mathrm{Pb}\left(\mathrm{Zr}_{0.53} \mathrm{Ti}_{0.47}\right) \mathrm{O}_{3}\right)$ 는 페로브스카이트(perovskite) 상 의 구조를 갖는 대표적인 압전 재료로서, 전기적 에너지 를 기계적 에너지로 변환하거나 기계적 에너지를 전기적 에너지로 상호변환이 가능하다. PZT 압전체는 유전특성 을 이용한 이동 통신기기의 핵심 소자부품, 압전성을 이 용한 마이크로 액츄에이터와 가속도센서, 그리고 초전성 을 이용한 적외선센서 소자 등에 널리 이용되고 있다. ${ }^{1-4)}$ 페로브스카이트 구조 세라믹은 우수한 압전 및 유전 특 성을 가지고 있어 여러 분야에 널리 사용되고 있지만, 세 라믹의 약한 강도와 곡선형상의 어려움, 벌크 형태로 인 한 디바이스 내의 일정 공간을 차지한다는 단점을 가지 고 있다. 이러한 단점을 극복하고자 최근 연구 개발 중인 PZT 섬유는 페로브스카이트의 구조를 가졌을 뿐 아니라 휘거나 구부렸을 때 박막에 비해 구조적 손상이 훨씬 덜

${ }^{\dagger}$ Corresponding author : Ji Sun Yun

E-mail : susubin@kicet.re.kr

Tel : +82-2-3282-2466 Fax : +82-2-3282-7816
하고, 압전 섬유를 연신이 가능한 substrate에 받아서 소자 를 만들 경우 stretchable 소자 제작도 가능하다. 또한 열 용량 감소, 높은 압전상수, 유연성, 기계적강도, 높은 민 감도, 미세크기 등의 장점으로 매우 선호 되는 형태이다.

일반적으로 $20 \mathrm{~nm} \sim 1 \mathrm{um}$ 의 직경 크기를 가지는 나노 섬유(Nano fiber)는 전구체 용액에 고전압(high voltage)을 걸어주어 컬렉터(collector)와 방사되는 팁(tip) 사이에 전 자기장(electrostatic force)을 형성시켜, 그 힘에 의해 낮은 점도 상태의 전구체 용액을 순간적으로 섬유형태로 방사 (spinning)하는 전기방사법(electrospinning)을 이용하여 제 조된다. ${ }^{5,6)}$ 이는 대량생산이 가능하며, 실험장치가 비교적 간단할 뿐만 아니라, 생산비용이 저렴하다. 또한 고분자 종류의 변화에 따라 나노 섬유의 구조 및 물성을 제어할 수 있다는 장점이 있다.

본 연구에서는 PZT의 기본조성 $\left(\mathrm{Pb}\left(\mathrm{Zr}_{0.53} \mathrm{Ti}_{0.47}\right) \mathrm{O}_{3}\right)$ 으로 sol-gel 합성법에 의하여 방사용액을 제조하였다. 기존의 다양한 연구에서 산성 분위기에서의 sol-gel 용액을 합성, 산의 종류 및 양에 따른 섬유 형상을 보고하였지만, ${ }^{7-9)}$ 본 연구에서는 PVP(polyvinylpyrrolidone)의 아민 그룹과 metalloxane polymer 사이의 강한 수소결합이 고온 소결 
과정 중 condensation 반응을 방해하여 섬유 형상 안정화 에 기여할 수 있도록 PVP를 사용하여 PZT sol-gel 용액 을 합성하였다. $\mathrm{Pb}, \mathrm{Zr}$, Ti 전구체 용액과 2-methoxyethanol, $\mathrm{PVP}$ 와 Acetylacetone를 혼합 및 열처리 후, electrospinning 장비를 이용하여 PZT 섬유를 방사하였다. 방사한 섬유의 소결 온도에 따른 결정화도를 $\mathrm{TGA}, \mathrm{XRD}$ 를 통하여 분석 하였고, 소결 후 PZT 섬유의 미세 구조는 FE-SEM, TEM 을 이용하여 분석하였다.

\section{2. 실험방법}

전기방사용 용액 PZT sol-gel 용액 합성 및 PZT 섬유를 방사하기 위해 Fig. 1(a)과 같은 공정을 진행하였다. PZT sol-gel 용액은 $\mathrm{Pb}\left(\mathrm{Zr}_{0.53} \mathrm{Ti}_{0.47}\right) \mathrm{O}_{3}$ 를 기본조성으로 용매로서

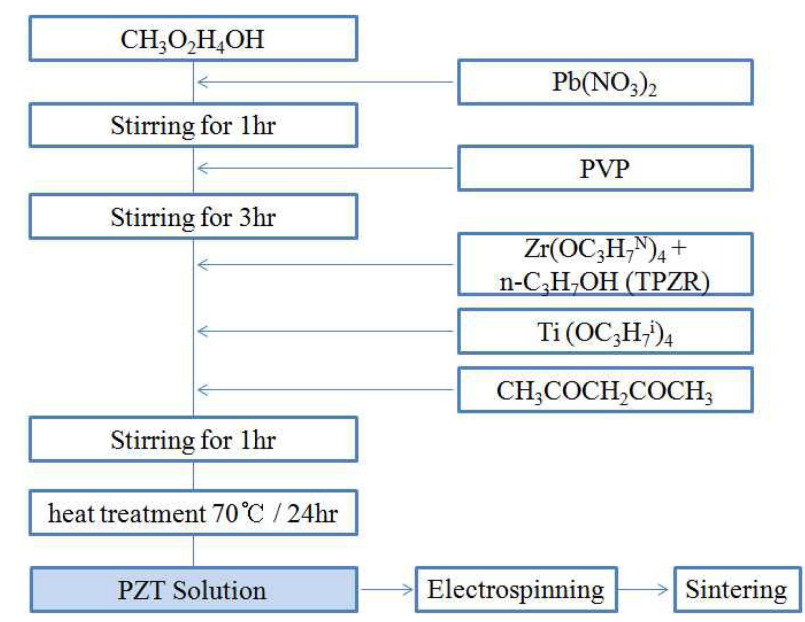

(a)

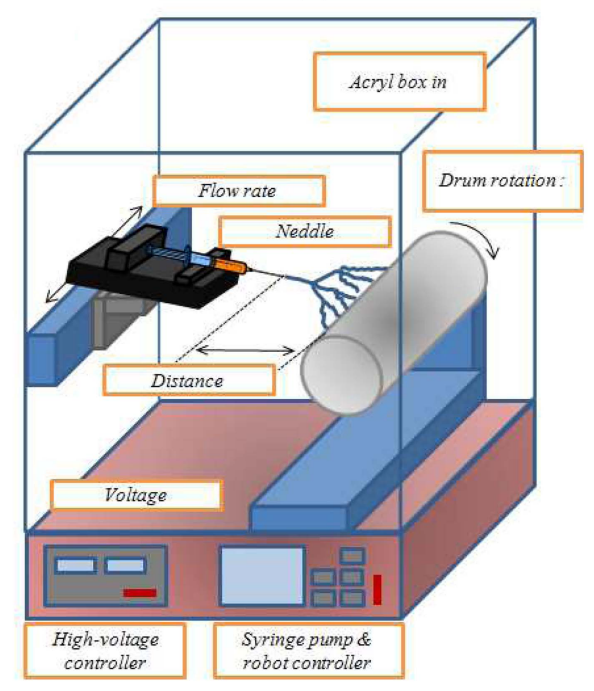

(b)

Fig. 1. (a) Schematic synthesis procedures of PZT sol-gel solution and PZT fiber and (b) schematic illustration of electrospinning device.
는 2-methoxyethanol과 첨가제로 $\mathrm{PVP}$ 와 Acetylacetone를 사용하였다. 먼저 2-Methoxyethanol과 $\mathrm{Pb}\left(\mathrm{NO}_{3}\right)_{2}$ 를 1시간 동안 교반시킨 후 $\mathrm{PVP}$ 를 첨가하여 다시 3시간 동안 교 반시킨다. $\mathrm{Zr}\left(\mathrm{OC}_{3} \mathrm{H}_{7}\right)_{4}, \mathrm{Ti}\left(\mathrm{OC}_{3} \mathrm{H}_{7}\right)_{4}$, Acetylacetone을 순차 적으로 첨가 후 1 시간 동안 교반시켜준다. ${ }^{10)}$ 이렇게 합성 된 PZT sol 용액을 gel화 시켜주기 위해 $70^{\circ} \mathrm{C}$ 에 1 시간 중 탕을 통한 열처리 공정을 진행하였다.

PZT 섬유를 제작하기 위해 Fig. 1(b)와 같은 electrospinning 장비를 이용하였다. 앞서 제작된 PZT 용액을 주 사기에 넣고 주사기 펌프를 이용하여 $30 \mathrm{ul} / \mathrm{min}$ 의 속도로 토출시켰다. 이때 노즐에 인가된 전압은 $14 \sim 18 \mathrm{kV}$ 이며 유리 기판과의 거리는 $10 \mathrm{~cm}$ 이다. 방사 후 $70^{\circ} \mathrm{C}$ 에서 24시 간동안 건조시킨 후 $5^{\circ} \mathrm{C} / \mathrm{min}$ 의 승온 속도로 3 가지의 다른 온도로(1) $400^{\circ} \mathrm{C} /$ (2) $400^{\circ} \mathrm{C}$ sintering $\rightarrow 550^{\circ} \mathrm{C}$ sintering / (3) $400^{\circ} \mathrm{C}$ sintering $\rightarrow 650^{\circ} \mathrm{C}$ sintering) 각각 30 분 동안 열처 리 하였다.

이렇게 제작된 PZT 분석하기 위해 TGA(Shimadzu / DTG-60H), XRD(Rigaku Corporation/D/max 2200V/PC), SEM (Jeol/JSM-6700F), TEM(Jeol/JEM-4010) 통하여 구조분석 및 특성평가를 수행하였다.

\section{3. 실험 결과 및 고찰}

Fig. 2(a)는 열처리 공정 전의 PZT 세라믹 입자, Fig. 2(b) 는 PZT sol 용액을 gel화시키기 위해 중탕을 통한 열처리 공정 후 합성된 PZT 세라믹 입자를 TGA/DTA 분석으로 부터 얻은 그래프이다. Fig. 2(a)의 TGA 결과는 중량이 $180^{\circ} \mathrm{C}$ 정도에서 급격하게 감소하였다가 $200^{\circ} \mathrm{C}$ 이후의 온 도부터 크게 변화가 없다는 것을 알 수 있다. $180^{\circ} \mathrm{C}$ 에서 질량이 급격히 감소하게 된 이유는 PZT sol-gel solution 에 함유되어 있는 PVP등의 유기물질이 제거되었기 때문 으로 판단된다. DTA 경우에는 결정화가 되는 흡열 피크 가 관찰 되지 않고 있어, 결정화가 진행되지 않음을 확인 할 수 있었다. 1시간 동안 열처리를 해주어 PZT sol 용액 을 gel화 시켜준 Fig. 2(b) 경우, Fig. 2(a)와 마찬가지로 $\mathrm{TGA}$ 결과를 보면 $200^{\circ} \mathrm{C}$ 에서 급격하게 질량이 감소한 후, $200^{\circ} \mathrm{C}$ 이후의 온도부터 서서히 일정하게 질량이 감소하 였다. Fig. 2(b)의 DTA 곡선에서는 $500^{\circ} \mathrm{C}$ 에서 $600^{\circ} \mathrm{C}$ 도 사 이의 경우에 흡열반응으로 외부로 열을 흡수하게 되면서 결정화가 진행되었다. 결국 열처리를 통한 gel화 공정이 결정화에 중요한 영향을 미친 다는 것을 알 수 있다. PZT 박막을 제조할 경우 gel화 공정 없이 스핀 코팅하여 제조 하여도 결정화에는 큰 문제가 없지만, ${ }^{10)}$ Fig. 2 결과에서 볼 수 있듯이 섬유 방사 공정에 있어서는 결정화를 위해 서는 방사 전의 추가적인 gel화 공정의 반드시 필요함을 확인할 수 있었다.

Fig. 3은 gel화 공정을 통하여 합성된 PZT sol-gel 용액 

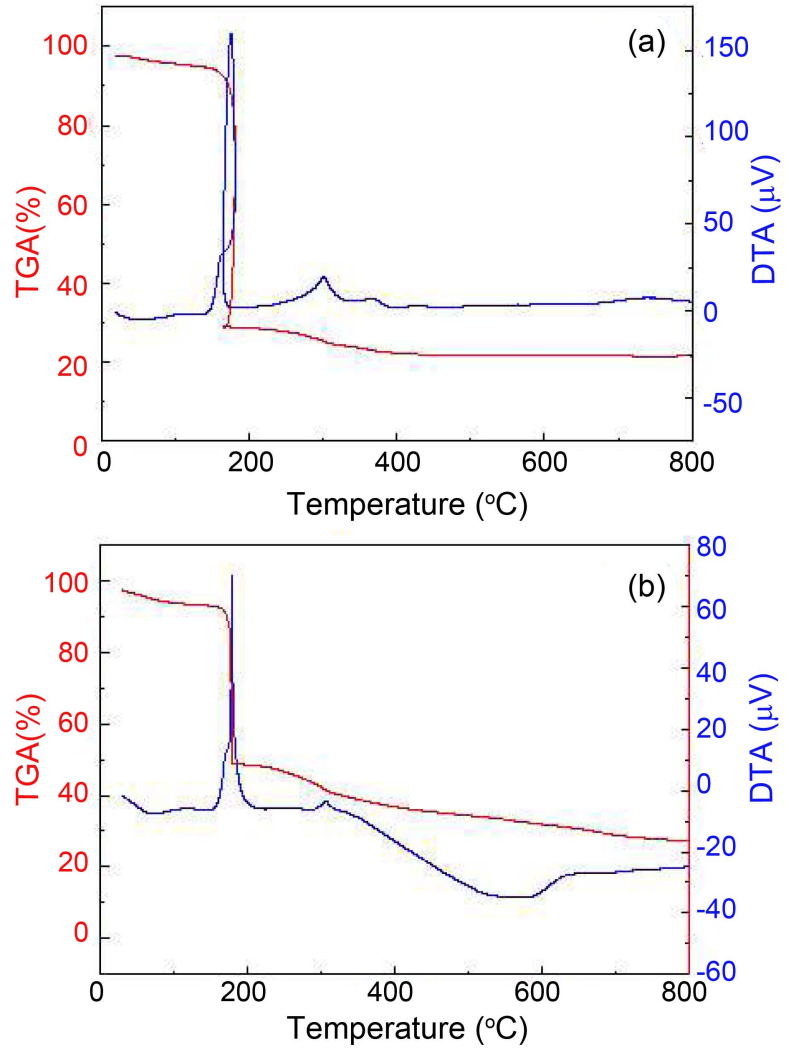

Fig. 2. TGA and DTA curves of (a) PZT (b) PZT after heat treatment.

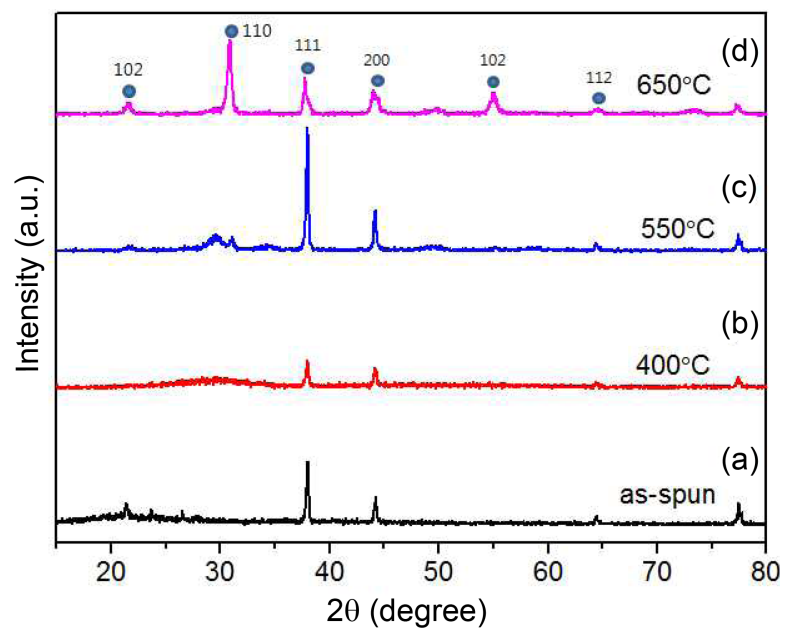

Fig. 3. XRD patterns of PZT nanofibers after heat treatment: (a) as-spun, (b) fibers sintering at $400^{\circ} \mathrm{C}$, (c) fibers sintering at $550^{\circ} \mathrm{C}$, and (d) fibers sintering at $650^{\circ} \mathrm{C}$.

의 XRD 패턴 구조를 분석 결과이다. Fig. 2의 TGA/DTA 측정 결과와 같이 방사 직후의 섬유 Fig. 3(a)와 500 $600^{\circ} \mathrm{C}$ 에서 결정화 진행 온도보다 낮은 온도에서 소결한 Fig. 3(b)의 경우는 결정화가 진행되지 않아 PZT의 페로 브스카이트의 결정상이 관찰되지 않았다. 결정화가 진행

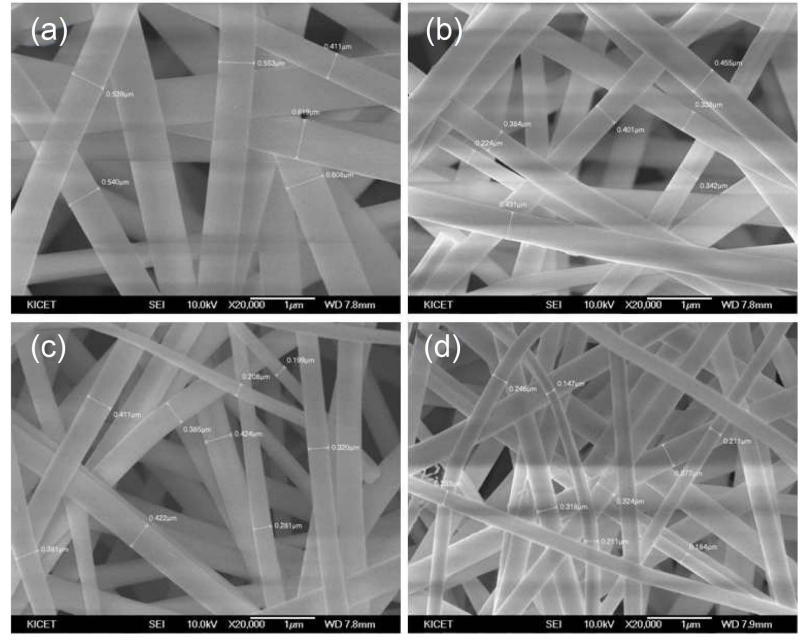

Fig. 4. SEM images of before sintering and after sintering: (a) as-spun, (b) sintering at $400^{\circ} \mathrm{C}$, (c) sintering at $550^{\circ} \mathrm{C}$, and (d) sintering at $650^{\circ} \mathrm{C}$.

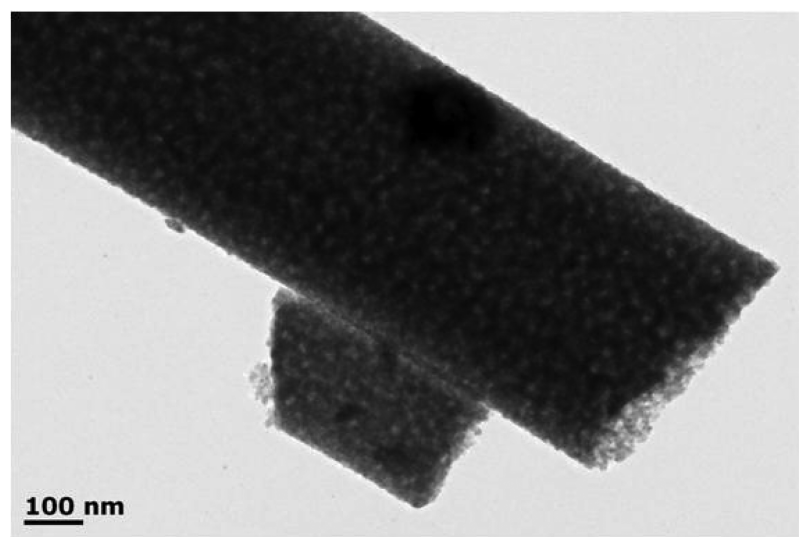

Fig. 5. TEM image of PZT fiber after sintering at $650^{\circ} \mathrm{C}$.

중인 $550^{\circ} \mathrm{C}$ 에서 소결한 Fig. 3(c)에서는 페로브스카이트 결정상과 이차상이 공존하는 것을 확인할 수 있었다. Fig. 1 의 결정화 진행온도 $\left(500 \sim 600^{\circ} \mathrm{C}\right)$ 이상인 $650^{\circ} \mathrm{C}$ 에서 소결 한 Fig. 3(d)의 경우에 페로브스카이트 단일 상을 갖는 것 을 알 수 있었다.

Fig. 4의 그림은 열처리 전과 열처리 온도에 따른 $\mathrm{PZT}$ 나노섬유의 FE-SEM 이미지를 보여준다. Fig. 4(a)의 방사 후 PZT 섬유는 평균 두께가 $545 \mathrm{~nm}$ 의 직경을 가지고 있 었다. $400^{\circ} \mathrm{C}$ 소결 후의 PZT 섬유인 Fig. 4(b)의 경우 유 기물질이 제거되면 평균 두께가 $357 \mathrm{~nm}$ 감소 한 것을 확 인 하였다. Fig. $4(\mathrm{c})$ 는 $550^{\circ} \mathrm{C}$ 소결은 결정화 진행 중인 온 도로 결정화 $\left(500 \sim 600^{\circ} \mathrm{C}\right)$ 가 진행되면서 수축이 일어나서 평균직경이 $295 \mathrm{~nm}$ 로 감소가 이루어 졌다. Fig. 4(d)의 $650^{\circ} \mathrm{C}$ 소결 후의 $\mathrm{PZT}$ 섬유는 결정화가 완료되어 지면서, 결정화에 따라 수축이 더 진행하며, 직경이 $224 \mathrm{~nm}$ 로 더 감소되었다. 이러한 경향성은 $650^{\circ} \mathrm{C}$ 소결 후의 $\mathrm{PZT}$ 섬유 의 TEM 이미지(Fig. 5)에서도 관찰되어진다. 섬유로 방사 
되어진 후 유기물질의 제거 및 결정화에 따른 수축에 따 라 섬유상 내부의 미세한 기공이 관찰되어지지만 일정한 패턴을 보여 결정성은 좋은 것을 확인 할 수 있었다.

\section{4. 결 론}

본 연구에서는 $\mathrm{Pb}\left(\mathrm{Zr}_{0.53} \mathrm{Ti}_{0.47}\right) \mathrm{O}_{3}$ 의 기본조성으로 섬유 형상 안정화에 기여할 수 있도록 $\mathrm{PVP}$ 를 사용하여 $\mathrm{PZT}$ sol-gel 용액을 합성하였다. 합성된 PZT sol-gel 용액을 electrospinning 장비를 이용하여 PZT 섬유를 방사하였고, PZT 섬유의 결정구조 및 미세 구조를 분석하였다. TGA 를 통해서 PZT 섬유가 결정화되기 위해서는 열처리를 통 한 gel화 공정이 반드시 필요함을 알 수 있었고, 온도는 $500^{\circ} \mathrm{C} \sim 600^{\circ} \mathrm{C}$ 흡열반응이 일어나면서 결정화가 되었다는 것을 알 수 있다. XRD에서는 다양한 온도에서 소결한 결 과 $650^{\circ} \mathrm{C}$ 에서 페로브스카이트 결정 구조를 가지게 되는 것을 확인할 수 있었다. 또한 열처리 과정 이후 소결 온 도가 증가함에 따라 나노 섬유의 직경이 감소하는 것을 확인 할 수 있었는데, 온도가 as-spun, $400^{\circ} \mathrm{C}, 550^{\circ} \mathrm{C}$, $650^{\circ} \mathrm{C}$ 로 증가할수록 평균직경은 $545 \mathrm{~nm}, 357 \mathrm{~nm}, 295 \mathrm{~nm}$, $224 \mathrm{~nm}$ 감소하는 것을 확인 할 수 있었다.

\section{REFERENCES}

1. M. Khajelakzay and T. N. Ehasn, "Synthesis and Characterization of $\mathrm{PB}\left(\mathrm{ZR}_{0.52} \mathrm{TI}_{0.48}\right) \mathrm{O}_{3}$ Nanofibers by Electrospinning and Dielectric Properties of PZT-Resin Composite," Mater. Lett., 75 61-64 (2012).
2. J. M. Byun, H. N. Lee, H. K. Lee, S. E. Lee, and H .C. Lee, "A Study on the Crystalline Orientation and Electric Properties of Sol-Gel PZT Thin Film for Piezoelectric Sensors (in Korean)," J. Kor. Sensors Soc., 19 202-08 (2010).

3. N. Dharmaraj, C. H. Kim, and H. Y. Kim, " $\mathrm{Pb}\left(\mathrm{Zr}_{0.5}, \mathrm{Ti}_{0.5}\right) \mathrm{O}_{3}$ Nanofibers by Electrospining," Mater. Lett., 59 [24-35] 3085-89 (2005).

4. S. Y. Xu, Y. Shi, and S. G. Kim, "Fabrication and Mechanical Property of Nano Piezoelectric Fibers," Nanotechnology, 17 [17] 4497-501 (2006).

5. J. Y. Hyeon, J. M. Choi, Y. S. Park, J. Kang, and J. H. Sok, "Characteristics of Electrospun Ag Nanofibers for Transparent Electrodes (in Korean)," J. Kor. Vacuum Soc., 22 156-61 (2013).

6. E. S Lee, W. K Lee, C. Y. Park, S. K. Min, and S. H. Jang, "Oil Absorbecies of Fibers of Biodegradable and Microbial Polymers Prepared by Electrospinning Method (in Korean)," J. Environ. Sci. Int., 22 243-49 (2013).

7. M. Zhang, I. M. Salvado, and P. M. Vilarinho, "The Effect of Acid Mixture on the Structure of Sol-Gel PZT Fibers," Mater. Lett., 57 [26-27] 4271-75 (2003).

8. M. Zhang, I. M. Salvado, and P. M. Vilarinho, "Synthesis and Characterization of Lead Zirconate Titanate Fibers Prepared by the Sol-Gel Method: The Role of the Acid," J. Am. Ceram. Soc., 86 [5] 775-81 (2003).

9. M. Hossain and A. Kim, "The Effect of Acetic Acid on Morphology of PZT Nanofibers Fabricated by Electrospinning," Mater. Lett., 63 [9-10] 789-92 (2009).

10. S. Takenaka and H. Kozuka, "Sol-Gel Preparation of Singlelayer, $0.75 \mathrm{~mm}$ Thick Lead Zirconate Titanate Films from Lead Nitrate-Titanium and Zirconium Alkoxide Solutions Containing Polyvinylpyrrolidone," Appl. Phys. Lett., 79 [21] 3485-87 (2001). 